\title{
ECM Characterization Reveals a Massive Activation of Acute Phase Response during FSGS
}

\author{
Eva Nora Bukosza ${ }^{1,2}$, Christoph Kornauth ${ }^{2,3}$, Karin Hummel ${ }^{4}$, Helga Schachner ${ }^{2}$, \\ Nicole Huttary ${ }^{2}$, Sigurd Krieger ${ }^{2}$, Katharina Nöbauer ${ }^{4}$, André Oszwald ${ }^{2}$, \\ Ebrahim Razzazi Fazeli ${ }^{4}$, Klaus Kratochwill ${ }^{5,6}(0)$, Christoph Aufricht ${ }^{6}$, Gabor Szénási ${ }^{1}$, \\ Peter Hamar ${ }^{1, \dagger}$ and Christoph A. Gebeshuber ${ }^{2, *,+}$
}

1 Institute of Translational Medicine, Semmelweis University Budapest, Túzoltó u 37-47, 1094 Budapest, Hungary; nora.bukosza@gmail.com (E.N.B.); szenasi.gabor@med.semmelweis-univ.hu (G.S.); hamar.peter@med.semmelweis-univ.hu (P.H.)

2 Clinical Institute for Pathology, Medical University Vienna, Währinger Gürtel 18-20, 1090 Vienna, Austria; Christoph.Kornauth@meduniwien.ac.at (C.K.); helga.schachner@meduniwien.ac.at (H.S.); nicole.huttary@meduniwien.ac.at (N.H.); sigurd.krieger@meduniwien.ac.at (S.K.); andre.oszwald@meduniwien.ac.at (A.O.)

3 Clinical Division of Hematology and Hemostaseology, Department of Internal Medicine I, Medical University Vienna, Währinger Gürtel 18-20, 1090 Vienna, Austria

4 Vetcore Facility for Research, University of Veterinary Medicine Vienna, Veterinärplatz 1, 1210 Vienna, Austria; karin.hummel@vetmeduni.ac.at (K.H.); katharina.noebauer@vetmeduni.ac.at (K.N.); ebrahim.razzazi@vetmeduni.ac.at (E.R.F.)

5 Christian Doppler Laboratory for Molecular Stress Research in Peritoneal Dialysis, Department of Pediatrics and Adolescent Medicine, Medical University of Vienna, 1210 Vienna, Austria;

klaus.kratochwill@meduniwien.ac.at

6 Division of Pediatric Nephrology and Gastroenterology, Department of Pediatrics and Adolescent Medicine, Medical University of Vienna, 1210 Vienna, Austria; christoph.aufricht@meduniwien.ac.at

* Correspondence: christoph.gebeshuber@meduniwien.ac.at; Tel.: +43-1-40400-51840

+ These authors contributed equally to this work.

Received: 9 February 2020; Accepted: 16 March 2020; Published: 18 March 2020

check for updates

\begin{abstract}
The glomerular basement membrane (GBM) and extra-cellular matrix (ECM) are essential to maintain a functional interaction between the glomerular podocytes and the fenestrated endothelial cells in the formation of the slit diaphragm for the filtration of blood. Dysregulation of ECM homeostasis can cause Focal segmental glomerulosclerosis (FSGS). Despite this central role, alterations in ECM composition during FSGS have not been analyzed in detail yet. Here, we characterized the ECM proteome changes in miR-193a-overexpressing mice, which suffer from FSGS due to suppression of Wilms' tumor 1 (WT1). By mass spectrometry we identified a massive activation of the acute phase response, especially the complement and fibrinogen pathways. Several protease inhibitors (ITIH1, SERPINA1, SERPINA3) were also strongly increased. Complementary analysis of RNA expression data from both miR-193a mice and human FSGS patients identified additional candidate genes also mainly involved in the acute phase response. In total, we identified more than 60 dysregulated, ECM-associated genes with potential relevance for FSGS progression. Our comprehensive analysis of a murine FSGS model and translational comparison with human data offers novel targets for FSGS therapy.
\end{abstract}

Keywords: FSGS; ECM; sclerosis; acute phase response; fibrinogen; complement system 


\section{Introduction}

The kidney glomerulus is essential for the filtration of blood. A sieve-like structure is formed by interdigitating foot processes of podocytes and underlying fenestrated endothelial cells. Those cellular components are separated by the glomerular basement membrane/extra-cellular matrix (GBM/ECM). The glomerular ECM provides a supporting scaffold for podocytes and endothelial cells and integrates signals between cells and their environment, including survival and growth factor signaling [1-3]. Dysregulation of ECM deposition and formation of excessive connective tissue histologically manifests as sclerosis and can cause organ dysfunction or failure [4], especially in glomerular diseases [5-7].

Focal segmental glomerulosclerosis (FSGS) refers to a histo-pathological pattern of injury characterized by sclerosis in some areas of some glomeruli [8,9]. Heterogeneous underlying causes (e.g., gene mutations, circulating factors, miRNAs, hypertension, drugs, viruses) invariably lead to the common ultrastructural denominator-podocyte foot process effacement-or podocyte loss, which clinically manifests as nephrotic range proteinuria. Some patients respond to corticosteroids or calcineurin inhibitors, but specific treatment is lacking [10]. FSGS frequently progresses to a common diagnostic endpoint defined by pronounced sclerotic lesions causing loss of glomerular function and end-stage renal disease (ESRD) [8,9]. Therefore, the elucidation of changes in the ECM composition during FSGS progression might be instrumental to gain a better understanding of these pathological processes and aid development of novel therapies.

Recently, the composition of the glomerular ECM of humans and mice have been established [11-13]. Furthermore, comparison of the glomerular ECM of mice with different genetic backgrounds and basic levels of proteinuria revealed changes in certain proteins, which might enhance disease susceptibility [7]. To gain deeper insight into the changes during FSGS development and progression, we characterized the ECM proteome during FSGS in the murine miR-193a transgenic model by mass spectrometry (MS) analysis. miR-193a-overexpression suppresses Wilms' tumor 1 (WT1), a transcription factor and master regulator of podocyte identity. Subsequently, this leads to the loss of many WT1 targets essential for podocyte differentiation and homeostasis, which ultimately causes FSGS and kidney failure [14]. We also found significantly enhanced levels of miR-193a in patients suffering from idiopathic FSGS [14]. We complemented our MS data with a candidate search of the RNA level in a murine FSGS model and human FSGS patient data.

\section{Results}

By adapting a protocol established by Rachel Lennon and coworkers $[7,11]$, we isolated the ECM of healthy control mice and mice over-expressing miR-193a for 8 weeks [14] (Figure 1a-d). The ECM of four mice per group was characterized by MS analysis.

HPLC-MS analysis identified 1593 proteins with at least two peptides over all samples (Table S1). Manual curation revealed 111 bona fide ECM-associated proteins according to the matrisome resource database [15] plus additional proteins not primarily associated with ECM (e.g., members of the complement pathway, see below) (Table S2). Our findings are in line with a comparable study identifying 115 ECM-associated proteins in two different mouse backgrounds [7]. We found strong and significant expression changes for 18 up- and two downregulated proteins in ECM isolates in miR-193a FSGS mice, four proteins were even exclusively detected in FSGS (Table 1.) 
a

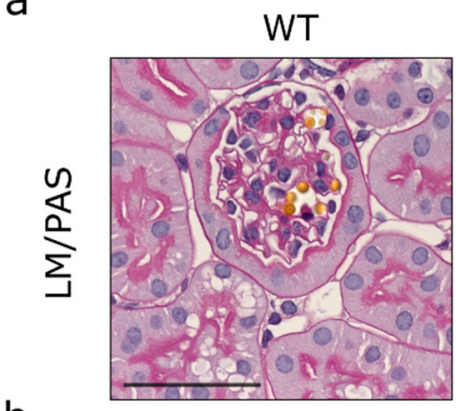

b

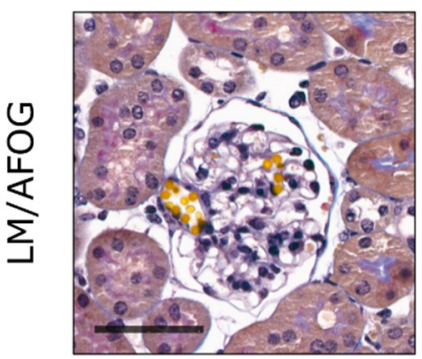

C

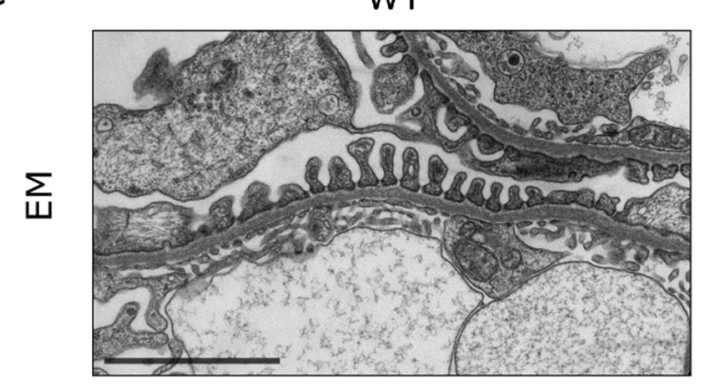

miR-193a
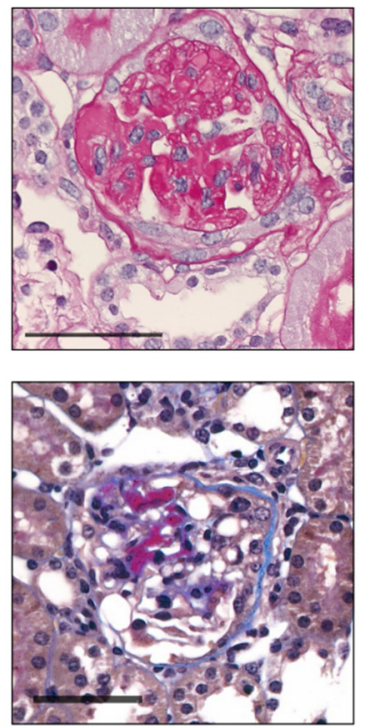

d



miR-193a

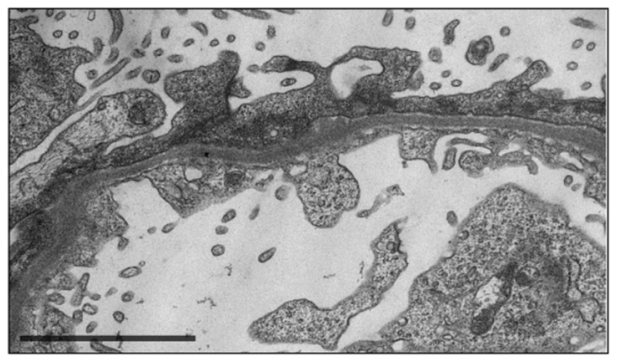

Figure 1. Kidney histology and albuminuria in miR-193a-driven focal segmental glomerulosclerosis (FSGS). Representative images of (a) Periodic-acid Schiff (PAS) and (b) trichromic Acid Fuchsin Orange G (AFOG) stainings of formalin-fixed paraffin-embedded (FFPE) sections show FSGS, intracapillary cast formation, and extracellular protein deposition in miR-193a mice 8 weeks post induction. (c) Electron-microscopy (EM) reveals podocyte foot process effacement, fusion, and detachment in miR-193a FSGS mice 8 weeks post induction of FSGS, but not wild-type control (WT). (d) Urinary albumin-to-creatinine ratio (UACR) in wild-type and miR-193a FSGS mice 8 weeks post induction is indicated in g/g. Light microscopy (LM) images scale bar $=100 \mu \mathrm{m}$; electron microscopy (EM) images scale bar $=2 \mu \mathrm{m}$; values represent means $\pm \mathrm{SD}, n \geq 5$ /group; unpaired two-tailed Student's t-test $* * *: p<0.0001$.

Especially the activation of the acute phase response in the miR-193a FSGS samples was evident: The complement components $\mathrm{C} 1 \mathrm{R}$ and $\mathrm{C} 4 \mathrm{~B}$, properdin $(\mathrm{CFP})$, and the complement activator $\mathrm{C}$-reactive protein (CRP) showed a massive increase in protein abundance while the complement membrane attack complex inhibitor CD59A was strongly reduced (Table 1). Furthermore, the fibrinogen $\alpha$-, $\beta-$, and $\gamma$-chains (FGA, FGB, FGG) were strongly upregulated during FSGS, although FGA failed to reach significance (Table 1, Table S1, Figure 2a,b). $\alpha$-globin (HBA1), $\beta 1$-globin (HBBB1), and $\beta 2$-globin (HBB-B2) were strongly enhanced, while the polymeric immunoglobulin receptor (PIGR) and the pulmonary surfactant-associated protein D (SFTPD) were even exclusively detected in the FSGS samples. 
Table 1. Significantly dysregulated genes in miR-193a-overexpressing glomeruli.

\begin{tabular}{cccc}
\hline ID & Symbol & Gene Name & FC \\
\hline P11680 & CFP & Properidin & $*$ \\
F8WJ05 & ITIH1 & Inter-alpha-trypsin inhibitor 1 & $*$ \\
O70570 & PIGR & Polymeric Immunoglobulin Receptor & $*$ \\
P50404 & SFTPD & Pulmonary surfactant-associated protein D & $*$ \\
Q56616 & C1R & Complement C1r & 27.8 \\
A8DUV3 & HBA1 & Hemoglobin subunit alpha 1 & 18.9 \\
Q3UER8 & FGG & Fibrinogen gamma chain & 15.4 \\
Q3TGR2 & FGB & Fibrinogen beta chain & 10.0 \\
Q91X17 & UMOD & Uromodulin & 8.8 \\
Q54AH9 & HBB-B2 & Hemoglobin subunit beta-2 & 8.7 \\
Q542I3 & CRP & C-reactive protein & 7.6 \\
A8DUK0 & HBB-B1 & Hemoglobin subunit beta-1 & 7.4 \\
P01029 & C4B & Complement C4-B & 6.2 \\
P07759 & SERPINA3 & Serine protease inhibitor A3K & 6.1 \\
A0A2P9DUN6 & SERPINA1 & Alpha-1-antitrypsin 1 & 5.6 \\
Q00623 & APOA1 & Apolipoprotein A-I & 5.3 \\
P11087 & COL1A1 & Collagen alpha-1(I) chain & 4.9 \\
Q8VBX5 & PPT1 & Palmitoyl-protein thioesterase 1 & 4.8 \\
Q9JMG7-2 & HDGFL3 & Hepatoma-derived growth factor-related protein 3 & -5.2 \\
O55186 & CD59A & CD59A glycoprotein & -5.7 \\
\hline
\end{tabular}

Differentially regulated genes were assessed by pairwise ratio comparison of glomeruli of miR-193a-overexpressing and wild-type mice; * not detectable in control samples; ID, protein accession number; FC, fold change miR-193a versus wild-type.

a



C
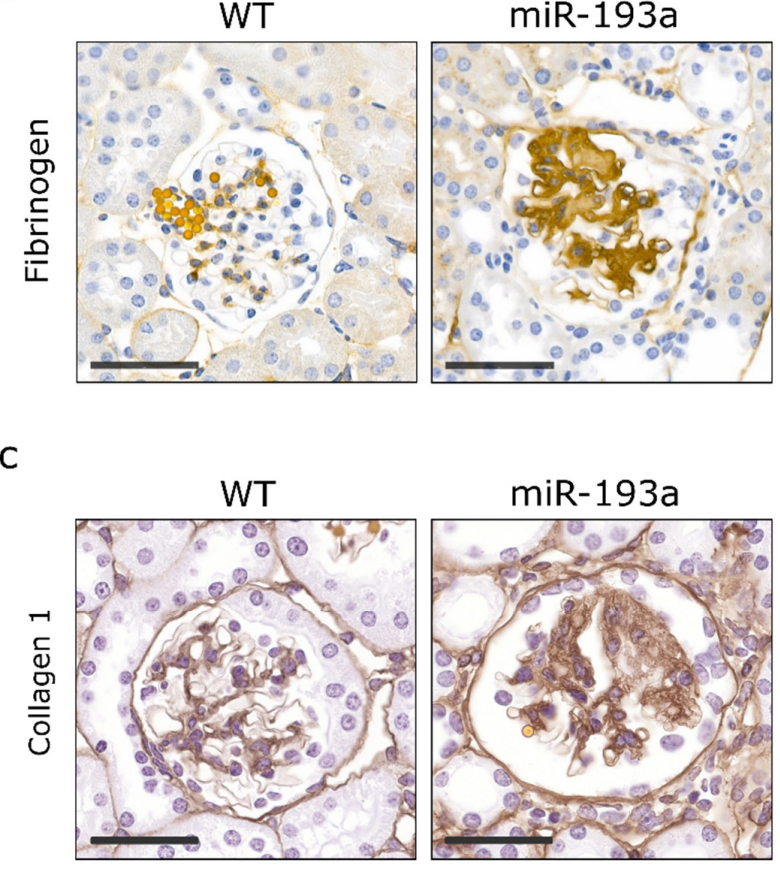

b

d
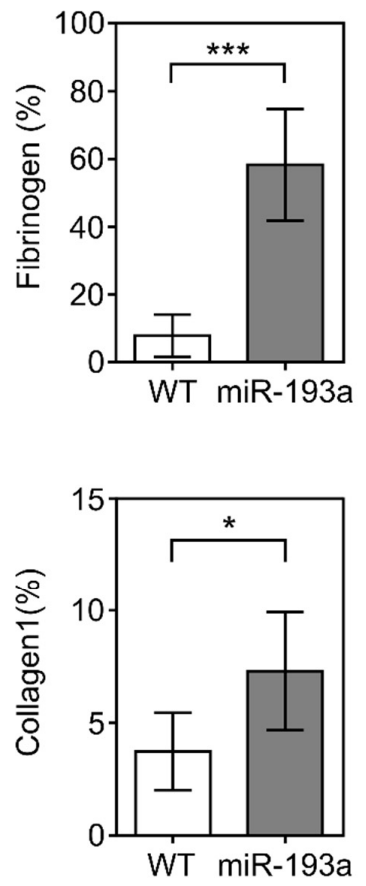

Figure 2. Fibrinogen and collagen 1 in a kidney glomerular matrix. (a) Representative images of FFPE sections stained for fibrinogen. (b) Fibrinogen-positive area in \% of total glomerular tuft area in wild-type control (WT) versus FSGS mice 8 weeks post miR-193a induction. (c) Representative images of FFPE sections stained for collagen 1. (d) Collagen 1-positive area in \% of total glomerular tuft area in wild-type control (WT) versus FSGS mice 8 weeks post miR-193a induction. For PAS and AFOG stainings of the respective sections, see Figure 1 . Scale bar $=50 \mu \mathrm{m}$; data represent means \pm SD, $n \geq 4$ samples/group, and each data point represents the mean of min. 10 glomeruli/sample; unpaired two-tailed Student's t-test ${ }^{*}: p<0.05 ;{ }^{* * *}: p<0.001$. 
Our study also revealed a strong increase in several plasma protease inhibitors (ITIH1, SERPINA1, SERPINA3) (Table 1). Protease inhibitors interfere with the turnover and degradation process of ECM material, thereby promoting sclerosis. In line with this, the sclerosis marker Colla1 was strongly upregulated in miR-193a-driven FSGS (Table 1, Figure 2c,d).

Upregulation was also observed for uromodulin (UMOD; Tamm-Horsfall protein), a master regulator of the immune system and cytokine production in the kidney [16] (Table 1).

In addition, Apolipoprotein A1 (APOA1) (Table 1), the apoprotein of the major high-density lipoprotein (HDL) in plasma was also strongly enhanced.

Hepatoma-Derived Growth Factor-Related Protein 3 (HDGFL3, HRP3) was the strongest down-regulated protein. HDGFL3 can be secreted and exerts mitogenic functions, especially on endothelial cells [17] (Table 1). Some of the GBM and core structural ECM proteins were also increased (including COL12A1, COL3A1, and TINAG), although significance was not reached (Table S1). Ingenuity pathway analysis confirmed activation of acute phase response as the most significant alteration (Figure 3).

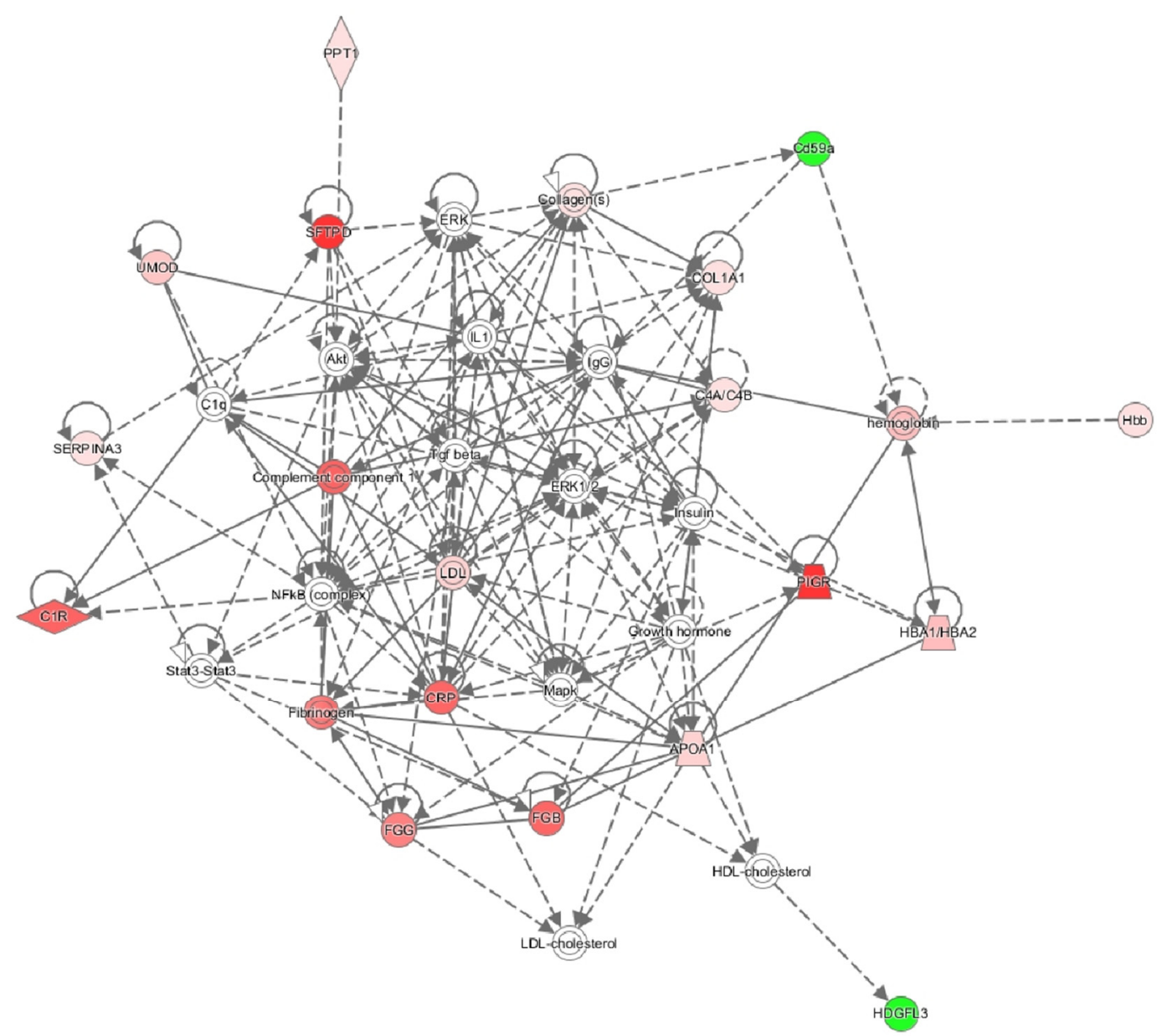

Figure 3. Network of the most strongly dysregulated proteins of the glomerular ECM in FSGS. The dysregulated genes from Table 1 and their interaction were analyzed by Ingenuity Pathway Analysis (red: downregulated; green: upregulated; stronger color means stronger regulation).

While MS-based analysis of the ECM identifies proteins independent of their origin-in our case several liver products were identified-it bears the risk of missing proteins with low abundance, weak ECM interaction, or generally unsuitable for MS analysis. To overcome the possible loss of such proteins from our analysis, in a second approach, we aimed to identify additional candidate ECM genes with relevance for FSGS. We overlapped genes $>$ 3-fold dysregulated in both miR-193a-overexpressing 
glomeruli five weeks post FSGS induction as published before by us [14] and of glomeruli of human FSGS patients published by the Potter group [18]. We verified the ECM-association of this overlap with the matrisome database [15] or by PubMed searches. This analysis suggested 32 up- and 5 downregulated ECM-associated genes with potential relevance for FSGS on the mRNA level (Table 2). In line with the MS data, several members of the complement cascade (CFI, C2/CFB, C7), UMOD, and SERPINA1 were also strongly upregulated on the RNA level, in both human and mouse FSGS (Table 2). Among the strongest upregulated genes on the RNA level were insulin growth factor binding protein 1 (IGFBP1), angiotensin converting enzyme 2 (ACE2), tubulointerstitial nephritis antigen (TINAG), and osteopontin (OPN, SPP1). The strongest downregulated gene was sclerostin (SOST), an inhibitor of bone morphogenic protein (BMP) signaling (Table 2). The podocyte survival factor vascular endothelial cell growth factor-alpha (VEGFA) was also lost (Table 2). Among the dysregulated genes were several involved in the regulation of the immune response and the coagulation cascade and genes associated with different cell signaling pathways (Wnt, TGF- $\beta$, IGF, VEGF) (Table 2).

Table 2. ECM genes dysregulated in glomeruli of miR-193a-driven FSGS and FSGS patient samples.



FC, linear fold change FSGS/control; ${ }^{1}$ miR-193 model, published by Gebeshuber et al. [14]; ${ }^{2}$ idiopathic FSGS patients, published by Bennett et al. [18].

\section{Discussion}

In this study, we tried to identify changes in the ECM during miR-193a-driven FSGS. We found a strong acute phase response including upregulation of the complement components $\mathrm{C} 1, \mathrm{C} 4 \mathrm{~B}, \mathrm{CFP}$, and 
CRP. It has been shown before that the complement system promotes inflammation and contributes to FSGS progression and is activated in patients with FSGS $[19,20]$ and that mesangial deposition of C4D is associated with poor renal survival in patients with primary FSGS [21]. This hyperactive complement cascade might also be responsible for the observed strong upregulation of $\alpha$-globin (HBA1), $\beta 1$-globin (HBB-B1), and $\beta 2$-globin (HBB-B2) (Table 1) through the lysis of erythrocytes, which in turn can lead to the production of reactive oxygen species (ROS). ROS have been shown to promote FSGS by different mechanisms, including the stimulation of apoptosis and the upregulation of the transient receptor potential cation channel TRPC6 [22]. Uromodulin is a part of the innate immune system and has been shown to bind to complement components and various cytokines [16].

Another pathway usually activated early after injury and interacting with the complement system is the fibrinogen pathway [23-25], which was as well upregulated during miR-193a-driven FSGS. Like complement components, fibrinogen is mostly produced in the liver and plays central roles in blood coagulation, the regulation of inflammation, cytokine expression, fibrosis, and apoptosis [26-28]. Fibrinogen is able to alter podocyte homeostasis by binding to Toll-like receptor 4 (TLR4), thereby stimulating p38 phosphorylation and NFKB activation [29]. Complement 3 and fibrinogen chains were also the proteins with the strongest increase in abundance in a recently published study about lipopolysaccharide-induced septic acute kidney injury [30], suggesting that the acute phase response is a very common reaction to kidney injury. PIGR, also associated with the innate immune response and involved in transport of Immunoglobulin A (IgA), was exclusively detected in FSGS samples. Interestingly, PIGR is involved in IgA nephritis and can be upregulated by TLR4 [31,32]. Another member of the innate immune response, SFTPD, was also exclusively detected in the ECM of miR-193a mice.

Furthermore, we found upregulation of several proteases (ITIH1, SERPINA1, SERPINA3), which can turnover ECM components and are therefore of central relevance for the sclerotic process. The HDL component APO1 was also increased in miR-193a-driven FSGS. APOA1 can promote cholesterol efflux, which is able to cause podocyte damage [33]. In general, altered lipid biology may harm podocytes via different pathways $[33,34]$. A high molecular weight form of APOA1 is a candidate for a circulating factor of recurrent FSGS [35,36]. APOA1 is a binding partner of APOL1, also implicated in FSGS [37].

To reveal additional candidates potentially overseen by MS analysis, we complemented our protein data with ECM-associated genes dysregulated on the RNA level in FSGS patient samples and glomeruli of the miR-193a model [14,18]. This revealed two overlapping candidates (UMOD, SERPINA1) and additional 35 ECM-associated FSGS candidate genes. In line with the MS data, several complement components were also upregulated. The strongest increase in the FSGS patient screen was found for osteopontin, a secreted glycophosphoprotein that can regulate many signaling processes highly relevant for the immune system and FSGS, including interleukins, NFкB, TGF- $\beta$, and CD44 [38]. High osteopontin levels were also found in Adriamycin nephropathy and FSGS patients $[39,40]$. The strongly upregulated genes IGFBP1 and IGFBP3 have been suggested as markers for diabetic nephropathy and chronic kidney disease [41,42]. Furthermore, we found several genes associated with the Wnt and TGF- $\beta$ pathway, both implicated in FSGS as well as ECM biology [43-45].

In summary, we analyzed the changes in the ECM composition during miR-193a-driven FSGS by MS analysis enhanced by an analysis of published RNA screens $[14,18]$. This combinatorial approach identified more than 60 ECM-associated genes dysregulated in FSGS, including several genes shared with other FSGS models and several novel ones, not discussed in the context of FSGS so far. The most apparent alterations were upregulation of the complement and fibrinogen pathway and of several protease inhibitors. In line with this, pharmacological intervention of thrombin-activated fibrinolysis inhibitor (TAFI) has been shown to ameliorate kidney fibrosis [46]. Therapeutic approaches targeting the complement or fibrinogen and coagulation pathway should therefore receive new attention for the treatment of FSGS. 


\section{Materials and Methods}

\subsection{Transgenic Mice}

miR-193a mice (in a Balb/c background) and the respective genotyping were described before [14]. Animal experiments were performed according to approvals from the Austrian Federal Ministry of Science and Research (66.009/0053-II/3b/2014).

\subsection{Isolation of Mouse Glomeruli and ECM}

Isolation was performed based on the magnetic bead method [47] with minor modifications. In brief, anaesthetized mice undertook a midline thoraco-abdominal incision; two ligations were placed, the first one closing the abdominal aorta together with the inferior cava vein below the branching point of the renal vessels, the other one closing the coeliac trunk together with the superior mesenteric artery. Both kidneys were perfused with $100 \mu \mathrm{L}\left(=4 \times 10^{7}\right)$ Dynabeads M-450 Tosylactivated (Invitrogen/Life Technologies AS, Oslo, Norway) in ice-cold HBSS $\left(\mathrm{Ca}^{2+}, \mathrm{Mg}^{2+}\right)$ via a polyethylene tubing extension on top of a $24 \mathrm{G}$ needle, inserted and secured into the upper abdominal aorta, while volume outflow was ensured by opening the distally ligated vena cava inferior (VCI). ECM extraction was performed according to a protocol established before [7].

\subsection{Glomerular ECM Sample Preparation for Analysis by Mass Spectrometry}

Proteins bound on the magnetic beads after the glomerular/ECM extraction was dissolved in $10 \mu \mathrm{L} 50 \mathrm{mM}$ TRIS (pH 8.0). For in-solution digestion, an additional $10 \mu \mathrm{L} 8 \mathrm{M}$ urea were added (total volume $20 \mu \mathrm{L}$ ). Digestion was performed after reduction with DTT for $30 \mathrm{~min}$ at $37^{\circ} \mathrm{C}$ and alkylation with iodoacetamide $\left(30 \mathrm{~min}, 25^{\circ} \mathrm{C}\right.$ ) using Trypsin/LysC (Promega Corporation, Madison, WI, USA). Digestion with LysC was performed at $37^{\circ} \mathrm{C}$ for $4 \mathrm{~h}$. To enable the trypsin digestion after $4 \mathrm{~h}$, the urea concentration was reduced with the addition of $140 \mu \mathrm{L} 50 \mathrm{mM}$ TRIS (pH 8.0). After an additional $8 \mathrm{~h}$ at $37^{\circ} \mathrm{C}$ the digest was stopped by the addition of $0.8 \mu \mathrm{L}$ of concentrated trifluoro acetic acid (TFA). The magnetic beads were removed, and peptides were collected. After the last sample preparation step, a clean-up of the peptides by C18 columns (Millipore Ziptips C18, Pierce Micro-Spin Columns, Pierce Biotechnology/Thermo Fisher Scientific, Rockford, IL, USA), peptides were injected into an HPLC-MS/MS system.

\subsection{Hybrid Quadrupole-Orbitrap Mass Spectrometry}

Proteins in the samples were identified and quantified using a high-resolution Hybrid Quadrupole-Orbitrap mass spectrometer (QExactive HF, Thermo Fisher Scientific, Waltham, MA, USA). Peptides were separated on a nano-HPLC Ultimate 3000 RSLC system (Dionex, Sunnyvale, CA, USA). Sample pre-concentration and desalting as well as separation of peptides were performed on a $25 \mathrm{~cm}$ Acclaim PepMap C18 column (75 $\mathrm{m}$ inner diameter, $3 \mu \mathrm{m}$ particle size, and $100 \AA$ pore size). The gradient started with $4 \%$ B (80\% acetonitrile (ACN) with $0.08 \%$ formic acid) and increased to $31 \%$ $\mathrm{B}$ in $60 \mathrm{~min}$ and to $44 \% \mathrm{~B}$ in an additional $5 \mathrm{~min}$. It was followed by a washing step with $95 \% \mathrm{~B}$. Mobile Phase A consisted of LC-MS grade $\mathrm{H}_{2} \mathrm{O}$ with $0.1 \%$ formic acid.

For mass spectrometric analysis applying data-dependent acquisition (DDA) the LC was directly coupled to a high-resolution Q Exactive HF Orbitrap mass spectrometer via a nano-electrospray ion source. MS full scans were performed in the ultrahigh-field Orbitrap mass analyzer in range of $m / z$ 350-2000 with a resolution of 60,000. Maximum injection time was $50 \mathrm{~ms}$ and the automatic gain control (AGC) was set to $3 \mathrm{e}^{\wedge} 6$. The top 10 intense ions were subjected to Orbitrap for further fragmentation via high energy collision dissociation (HCD) activation over a mass range between $\mathrm{m} / \mathrm{z}$ 200 and 2000 at a resolution of 15,000 with the intensity threshold at $4 \mathrm{e}^{\wedge} 4$. Ions with charge state +1 , $+7,+8$, and $>+8$ were excluded. Normalized collision energy (NCE) was set at 28 . For each scan, the AGC was set at $5 \mathrm{e}^{\wedge} 4$ and the maximum injection time was $50 \mathrm{~ms}$. Dynamic exclusion of precursor ion 
masses over a time window of 30s was used to suppress repeated peak fragmentation. The LC-MS system was operated by Xcalibur 4.1.31.9 (Thermo Scientific, Waltham, MA, USA).

\subsection{Data Processing for Protein Identification and Quantification}

Acquired raw data was processed with the vendor specific platform for protein identification and quantification (Proteome Discoverer software, version 2.2.0.388, Thermo Fisher Scientific, San Jose, CA, USA). The database consisted of UniProt entries of Mus musculus (taxonomy id: 10090) as well as cRAP (common Repository of Adventitious Proteins: ftp://ftp.thegpm.org/fasta/cRAP/crap.fasta). Database search parameters applied were trypsin digestion, cysteine alkylation set to iodoacetamide. As dynamic modifications oxidation on methionine and $\mathrm{N}$-terminal acetylation were allowed. Mass tolerance was $10 \mathrm{ppm}$, and fragment mass tolerance $0.02 \mathrm{Da}$. False discovery rate (FDR) performed using the integrated software tools was set to below $1 \%$ on peptide spectrum match (PSM) level and the minimal number of identified peptides per protein was set to 2 .

For quantification DDA-Orbitrap data abundances of peptides were extracted from raw data using Proteome Discoverer. Raw abundances were normalized to the same peptide amount. Biological replicate abundances were calculated as the median of the technical replicate abundances. The study design of the statistical analysis was a non-nested approach based on pairwise ratios of the normalized, scaled abundances, comparing samples of the two treatments "Control" and "m193" and taking into account the four independent biological replicates per group. Peptide group ratios were calculated with the software Proteome Discoverer as the geometric median of all combinations of ratios from all the replicates ("m193"|"Control"). Protein ratios subsequently are the geometric median of the peptide group ratios. The $p$-values were adjusted with the Benjamini-Hochberg method. Protein level changes were considered statistically significant if the FDR-adjusted $p$-value was lower than 0.05 , the fold change was at least two (fold change $<-2$ or $>+2$ ), and a minimum of one unique and at least two total peptides per protein.

\subsection{RNA Data Analysis and Human Data}

To extend the list of ECM-associated genes with genes not identified by MS-based analysis we manually compared genes at least 3-fold dysregulated in both miR-193a-driven FSGS and in glomeruli of human FSGS patients. ECM-association was determined by comparison to the matrisome resource database [15] and PubMed searches. More detailed data on the human samples were published before [18]. All FSGS samples were from patients with idiopathic FSGS. Controls were from "normal" regions of kidneys removed from Wilms' tumor patients $>4$ years of age $(n=3)$. All 4 FSGS patients were female, ranging in age from 17 to 29 , and 2 were Caucasian and 2 African-American. The FSGS needle biopsy samples typically included $2-15$ glomeruli. Urinary protein levels were 4.0, 5.4, 14.7, and $17.0(\mathrm{~g} /$ day) and serum creatinine levels were $0.8,1.1,0.9$, and $5.3(\mathrm{mg} / \mathrm{dL})$.

\subsection{Histology and Antibody Stainings}

Routine stainings (Periodic-Acid-Schiff, PAS; Acid Fuchsin Orange G AFOG) were performed on formalin-fixed paraffin-embedded histology samples after deparaffinization according to standard protocols. Immunohistochemistry were performed with the anti-collagen1 antibody (ab34710/Abcam, Cambridge, UK) and anti-fibrinogen antibody (Dako A0080/Agilent, Santa Clara, CA, USA) according to the manufacturer's protocol.

\subsection{Patents}

There are no patents resulting from the work reported in this manuscript.

Supplementary Materials: Supplementary materials can be found at http://www.mdpi.com/1422-0067/21/6/2095/s1.

Author Contributions: Conceptualization, C.A.G.; methodology, E.N.B., C.K., K.H., H.S., N.H., S.K., K.N., A.O., E.R.F.; validation, E.N.B., P.H., C.A.G.; formal analysis, E.N.B., K.H., P.H., C.A.G.; investigation, E.N.B., C.K., K.H., 
K.N., H.S., N.H.; resources, K.K., C.A., P.H., C.A.G.; writing-original draft preparation, C.A.G.; writing-review and editing, E.N.B., C.K., K.K., C.A., G.S., P.H.; visualization, E.N.B., C.A.G.; supervision, P.H., C.A.G.; project administration, C.A.G.; funding acquisition, K.K., C.A., P.H., C.A.G. All authors have read and agreed to the published version of the manuscript.

Funding: C.A.G and N.B. were funded by FWF grant P26967-B20. This research was funded by the Hungarian Scientific Research Fund: OTKA SNN-114619 (PH), ANN-110810 (PH), by the National Research, Development and Innovation Fund of Hungary: NVKP_16-1-2016-0042 (PH), by the Human Resources Development Operative Program in Hungary: EFOP-3.6.3-VEKOP-16-2017-00009, the Economic Development and Innovation Operative Program Grant: GINOP 2.3.2-15-2016-00048 (PH) the Kispál Gyula startup grant (300021) of the University of Pécs (PH). The Action Austria-Hungary Foundation (Stiftung Aktion Österreich-Ungarn, Wissenschafts- und Erziehungskooperation (Stiftung AÖU - 90 ÖU15) supported N.B. and P.H., K.K. was funded by the Austrian Federal Ministry of Science, Research and Economy and the National Foundation for Research, Technology and Development.

Acknowledgments: This research was supported using resources of the VetCore Facility (Proteomics) of the University of Veterinary Medicine Vienna.

Conflicts of Interest: The authors declare no conflict of interest. The funders had no role in the design of the study; in the collection, analyses, or interpretation of data; in the writing of the manuscript, or in the decision to publish the results.

\section{Abbreviations}

\begin{tabular}{|c|c|}
\hline ACE2 & angiotensin converting enzyme 2 \\
\hline AGC & automatic gain control \\
\hline APOA1 & Apolipoprotein A1 \\
\hline $\mathrm{BMP}$ & bone morphogenic protein \\
\hline CFP & properdin \\
\hline Col1a1 & collagen 1 \\
\hline COL12A1 & collagen type XII, alpha- 1 chain \\
\hline COL3A1 & collagen type III, alpha- 1 chain \\
\hline CRP & C-reactive protein \\
\hline $\mathrm{C} 1 \mathrm{R}$ & complement $\mathrm{C} 1 \mathrm{r}$ \\
\hline $\mathrm{C} 4 \mathrm{~B}$ & complement C4-B \\
\hline DDA & data-dependent acquisition \\
\hline DTT & dithiotreitol, 1,4-bis-(sulfanil)-butan-2,3-diol \\
\hline ECM & extra-cellular matrix \\
\hline ESRD & end-stage renal disease \\
\hline FGA, FGB, FGG & fibrinogen $\alpha, \beta$ and $\gamma$ chains \\
\hline FSGS & focal segmental glomerulosclerosis \\
\hline GBM & glomerular basement membrane \\
\hline HBA1 & $\alpha$-globin \\
\hline HBB-B1 & $\beta 1$-globin \\
\hline HBB-B2 & $\beta 2$-globin \\
\hline HBSS & Hank's Balanced Salt Solution \\
\hline HCD & high energy collision dissociation \\
\hline HDGFL3, HRP3 & Hepatoma-Derived Growth Factor-Related Protein 3 \\
\hline HDL & high-density lipoprotein \\
\hline HPLC-MS & high-performance liquid chromatography mass spectrometry \\
\hline ITIH1 & Inter-alpha-trypsin inhibitor heavy chain $\mathrm{H} 1$ \\
\hline IGF & insulin-like growth factor \\
\hline IGFBP1 & insulin growth factor binding protein 1 \\
\hline MS & mass spectrometry \\
\hline NCE & normalized collision energy \\
\hline NFKB & nuclear factor $\kappa \mathrm{B}$ \\
\hline PIGR & Polymeric immunoglobulin receptor \\
\hline PPT1 & Palmitoyl-protein thioesterase 1 \\
\hline
\end{tabular}




$\begin{array}{ll}\text { RNA } & \text { ribonucleic acid } \\ \text { ROS } & \text { reactive oxygen species } \\ \text { TFA } & \text { trifluoro acetic acid } \\ \text { TGF- } \beta & \text { transformin growth factor beta } \\ \text { TLR4 } & \text { Toll-like receptor 4 } \\ \text { SERPINA1 } & \text { serine proteinase A1 } \\ \text { SERPINA3 } & \text { serine proteinase A3 } \\ \text { SFTPD } & \text { pulmonary surfactant-associated protein D } \\ \text { SOST } & \text { sclerostin } \\ \text { SPP1 } & \text { osteopontin } \\ \text { TINAG } & \text { tubulointerstitial nephritis antigen } \\ \text { UMOD } & \text { Uromodulin, Tamm-Horsfall protein } \\ \text { VEGFA } & \text { vascular endothelial cell growth factor-alpha } \\ \text { WT1 } & \text { Wilms' tumor 1 }\end{array}$

\section{References}

1. Lennon, R.; Randles, M.J.; Humphries, M.J. The Importance of Podocyte Adhesion for a Healthy Glomerulus. Front. Endocrinol. 2014, 5, 160. [CrossRef] [PubMed]

2. Liu, J.; Wang, W. Genetic basis of adult-onset nephrotic syndrome and focal segmental glomerulosclerosis. Front. Med. 2017, 11, 333-339. [CrossRef] [PubMed]

3. Randles, M.J.; Humphries, M.J.; Lennon, R. Proteomic definitions of basement membrane composition in health and disease. Matrix Biol. 2017, 57-58, 12-28. [CrossRef] [PubMed]

4. Lu, P.; Takai, K.; Weaver, V.M.; Werb, Z. Extracellular matrix degradation and remodeling in development and disease. Cold Spring Harb. Perspect. Biol. 2011, 3, a005058. [CrossRef] [PubMed]

5. Sachs, N.; Sonnenberg, A. Cell-matrix adhesion of podocytes in physiology and disease. Nat. Rev. Nephrol. 2013, 9, 200-210. [CrossRef] [PubMed]

6. Pozzi, A.; Voziyan, P.A.; Hudson, B.G.; Zent, R. Regulation of matrix synthesis, remodeling and accumulation in glomerulosclerosis. Curr. Pharm. Des. 2009, 15, 1318-1333. [CrossRef]

7. Randles, M.J.; Woolf, A.S.; Huang, J.L.; Byron, A.; Humphries, J.D.; Price, K.L.; Kolatsi-Joannou, M.; Collinson, S.; Denny, T.; Knight, D.; et al. Genetic Background is a Key Determinant of Glomerular Extracellular Matrix Composition and Organization. J. Am. Soc. Nephrol. 2015, 26, 3021-3034. [CrossRef]

8. Fogo, A.B. Causes and pathogenesis of focal segmental glomerulosclerosis. Nat. Rev. Nephrol. 2014, 11, 76-87. [CrossRef]

9. Jefferson, J.A.; Shankland, S.J. The Pathogenesis of Focal Segmental Glomerulosclerosis. Adv. Chronic Kidney Dis. 2014, 21, 408-416. [CrossRef]

10. Malaga-Dieguez, L.; Bouhassira, D.; Gipson, D.; Trachtman, H. Novel Therapies for FSGS: Preclinical and Clinical Studies. Adv. Chronic Kidney Dis. 2015, 22, e1-e6. [CrossRef]

11. Lennon, R.; Byron, A.; Humphries, J.D.; Randles, M.J.; Carisey, A.; Murphy, S.; Knight, D.; Brenchley, P.E.; Zent, R.; Humphries, M.J. Global Analysis Reveals the Complexity of the Human Glomerular Extracellular Matrix. J. Am. Soc. Nephrol. 2014, 25, 939-951. [CrossRef]

12. Byron, A.; Randles, M.J.; Humphries, J.D.; Mironov, A.; Hamidi, H.; Harris, S.; Mathieson, P.W.; Saleem, M.A.; Satchell, S.C.; Zent, R.; et al. Glomerular Cell Cross-Talk Influences Composition and Assembly of Extracellular Matrix. J. Am. Soc. Nephrol. 2014, 25, 953-966. [CrossRef] [PubMed]

13. Hobeika, L.; Barati, M.T.; Caster, D.J.; McLeish, K.R.; Merchant, M.L. Characterization of glomerular extracellular matrix by proteomic analysis of laser-captured microdissected glomeruli. Kidney Int. 2017, 91, 501-511. [CrossRef] [PubMed]

14. Gebeshuber, C.A.; Kornauth, C.; Dong, L.; Sierig, R.; Seibler, J.; Reiss, M.; Tauber, S.; Bilban, M.; Wang, S.; Kain, R.; et al. Focal segmental glomerulosclerosis is induced by microRNA-193a and its downregulation of WT1. Nat. Med. 2013, 19, 481-487. [CrossRef] [PubMed]

15. Naba, A.; Clauser, K.R.; Hoersch, S.; Liu, H.; Carr, S.A.; Hynes, R.O. The matrisome: In silico definition and in vivo characterization by proteomics of normal and tumor extracellular matrices. Mol. Cell Proteom. 2012, 11. [CrossRef] 
16. Wu, T.-H.; Li, K.-J.; Yu, C.-L.; Tsai, C.-Y. Tamm-Horsfall Protein is a Potent Immunomodulatory Molecule and a Disease Biomarker in the Urinary System. Molecules 2018, 23, 200. [CrossRef]

17. LeBlanc, M.E.; Wang, W.; Caberoy, N.B.; Chen, X.; Guo, F.; Alvarado, G.; Shen, C.; Wang, F.; Wang, H.; Chen, R.; et al. Hepatoma-derived growth factor-related protein-3 is a novel angiogenic factor. PLoS ONE 2015, 10, e0127904. [CrossRef]

18. Bennett, M.R.; Czech, K.A.; Arend, L.J.; Witte, D.P.; Devarajan, P.; Potter, S.S. Laser capture microdissection-microarray analysis of focal segmental glomerulosclerosis glomeruli. Nephron Exp. Nephrol. 2007, 107, e30-e40. [CrossRef]

19. Strassheim, D.; Renner, B.; Panzer, S.; Fuquay, R.; Kulik, L.; Ljubanović, D.; Holers, V.M.; Thurman, J.M. IgM contributes to glomerular injury in FSGS. J. Am. Soc. Nephrol. 2013, 24, 393-406. [CrossRef]

20. Thurman, J.M.; Wong, M.; Renner, B.; Frazer-Abel, A.; Giclas, P.C.; Joy, M.S.; Jalal, D.; Radeva, M.K.; Gassman, J.; Gipson, D.S.; et al. Complement Activation in Patients with Focal Segmental Glomerulosclerosis. PLoS ONE 2015, 10, e0136558. [CrossRef]

21. Heybeli, C.; Oktan, M.A.; Yıldız, S.; Ünlü, M.; Celik, A.; Sarıoglu, S. Mesangial C4d deposition is independently associated with poor renal survival in patients with primary focal segmental glomerulosclerosis. Clin. Exp. Nephrol. 2019, 23, 650-660. [CrossRef] [PubMed]

22. Wang, Z.; Wei, X.; Zhang, Y.; Ma, X.; Li, B.; Zhang, S.; Du, P.; Zhang, X.; Yi, F. NADPH oxidase-derived ROS contributes to upregulation of TRPC6 expression in puromycin aminonucleoside-induced podocyte injury. Cell. Physiol. Biochem. 2009, 24, 619-626. [CrossRef] [PubMed]

23. Amara, U.; Rittirsch, D.; Flierl, M.; Bruckner, U.; Klos, A.; Gebhard, F.; Lambris, J.D.; Huber-Lang, M. Interaction between the coagulation and complement system. Adv. Exp. Med. Biol. 2008, 632, 71-79. [PubMed]

24. Auger, J.L.; Haasken, S.; Binstadt, B.A. Autoantibody-mediated arthritis in the absence of C3 and activating Fc $\gamma$ receptors: C5 is activated by the coagulation cascade. Arthritis Res. Ther. 2012, 14, R269. [CrossRef] [PubMed]

25. Subramaniam, S.; Jurk, K.; Hobohm, L.; Jäckel, S.; Saffarzadeh, M.; Schwierczek, K.; Wenzel, P.; Langer, F.; Reinhardt, C.; Ruf, W. Distinct contributions of complement factors to platelet activation and fibrin formation in venous thrombus development. Blood 2017, 129, 2291-2302. [CrossRef]

26. Rubel, C.; Fernández, G.C.; Dran, G.; Bompadre, M.B.; Isturiz, M.A.; Palermo, M.S. Fibrinogen promotes neutrophil activation and delays apoptosis. J. Immunol. 2001, 166, 2002-2010. [CrossRef]

27. Banas, M.C.; Banas, B.; Hudkins, K.L.; Wietecha, T.A.; Iyoda, M.; Bock, E.; Hauser, P.; Pippin, J.W.; Shankland, S.J.; Smith, K.D.; et al. TLR4 links podocytes with the innate immune system to mediate glomerular injury. J. Am. Soc. Nephrol. 2008, 19, 704-713. [CrossRef]

28. Sörensen, I.; Susnik, N.; Inhester, T.; Degen, J.L.; Melk, A.; Haller, H.; Schmitt, R. Fibrinogen, acting as a mitogen for tubulointerstitial fibroblasts, promotes renal fibrosis. Kidney Int. 2011, 80, 1035-1044. [CrossRef]

29. Wang, H.; Zheng, C.; Xu, X.; Zhao, Y.; Lu, Y.; Liu, Z. Fibrinogen links podocyte injury with Toll-like receptor 4 and is associated with disease activity in FSGS patients. Nephrology 2018, 23, 418-429. [CrossRef]

30. Róka, B.; Tod, P.; Kaucsár, T.; Vizovišek, M.; Vidmar, R.; Turk, B.; Fonović, M.; Szénási, G.; Hamar, P. The Acute Phase Response Is a Prominent Renal Proteome Change in Sepsis in Mice. Int. J. Mol. Sci. 2019, $21,200$. [CrossRef]

31. Schneeman, T.A.; Bruno, M.E.C.; Schjerven, H.; Johansen, F.-E.; Chady, L.; Kaetzel, C.S. Regulation of the polymeric Ig receptor by signaling through TLRs 3 and 4: Linking innate and adaptive immune responses. J. Immunol. 2005, 175, 376-384. [CrossRef]

32. Narita, I.; Kondo, D.; Goto, S.; Saito, N.; Watanabe, Y.; Yamazaki, H.; Sakatsume, M.; Saito, A.; Gejyo, F. Association of gene polymorphism of polymeric immunoglobulin receptor and IgA nephropathy. Intern. Med. 2001, 40, 867-872. [CrossRef]

33. Herman-Edelstein, M.; Scherzer, P.; Tobar, A.; Levi, M.; Gafter, U. Altered renal lipid metabolism and renal lipid accumulation in human diabetic nephropathy. J. Lipid Res. 2014, 55, 561-572. [CrossRef]

34. Fornoni, A.; Merscher, S.; Kopp, J.B. Lipid biology of the podocyte-new perspectives offer new opportunities. Nat. Rev. Nephrol. 2014, 10, 379-388. [CrossRef] 
35. Lopez-Hellin, J.; Cantarell, C.; Jimeno, L.; Sanchez-Fructuoso, A.; Puig-Gay, N.; Guirado, L.; Vilariño, N.; Gonzalez-Roncero, F.M.; Mazuecos, A.; Lauzurica, R.; et al. A form of apolipoprotein a-I is found specifically in relapses of focal segmental glomerulosclerosis following transplantation. Am. J. Transpl. 2013, 13, 493-500. [CrossRef]

36. Puig-Gay, N.; Jacobs-Cacha, C.; Sellarès, J.; Guirado, L.; González Roncero, F.; Jiménez, C.; Zárraga, S.; Paul, J.; Lauzurica, R.; Alonso, Á.; et al. Apolipoprotein A-Ib as a biomarker of focal segmental glomerulosclerosis recurrence after kidney transplantation: Diagnostic performance and assessment of its prognostic value-A multi-centre cohort study. Transpl. Int. 2019, 32,313-322. [CrossRef]

37. Freedman, B.I.; Kopp, J.B.; Langefeld, C.D.; Genovese, G.; Friedman, D.J.; Nelson, G.W.; Winkler, C.A.; Bowden, D.W.; Pollak, M.R. The apolipoprotein L1 (APOL1) gene and nondiabetic nephropathy in African Americans. J. Am. Soc. Nephrol. 2010, 21, 1422-1426. [CrossRef] [PubMed]

38. Icer, M.A.; Gezmen-Karadag, M. The multiple functions and mechanisms of osteopontin. Clin. Biochem. 2018, 59, 17-24. [CrossRef]

39. Shui, H.-A.; Ka, S.-M.; Yang, S.-M.; Lin, Y.-F.; Lo, Y.-F.; Chen, A. Osteopontin as an injury marker expressing in epithelial hyperplasia lesions helpful in prognosis of focal segmental glomerulosclerosis. Transl. Res. 2007, 150, 216-222. [CrossRef] [PubMed]

40. Wasilewska, A.; Taranta-Janusz, K.; Kuroczycka-Saniutycz, E.; Zoch-Zwierz, W. Urinary OPN excretion in children with glomerular proteinuria. Adv. Med. Sci. 2011, 56, 193-199. [CrossRef] [PubMed]

41. Al Shawaf, E.; Abu-Farha, M.; Devarajan, S.; Alsairafi, Z.; Al-Khairi, I.; Cherian, P.; Ali, H.; Mathur, A.; Al-Mulla, F.; Al Attar, A.; et al. ANGPTL4: A Predictive Marker for Diabetic Nephropathy. J. Diabetes Res. 2019, 2019, 4943191. [CrossRef] [PubMed]

42. Sayanthooran, S.; Magana-Arachchi, D.N.; Gunerathne, L.; Abeysekera, T. Potential diagnostic biomarkers for chronic kidney disease of unknown etiology (CKDu) in Sri Lanka: A pilot study. BMC Nephrol. 2017, 18, 31. [CrossRef] [PubMed]

43. Dai, C.; Stolz, D.B.; Kiss, L.P.; Monga, S.P.; Holzman, L.B.; Liu, Y. Wnt/beta-catenin signaling promotes podocyte dysfunction and albuminuria. J. Am. Soc. Nephrol. 2009, 20, 1997-2008. [CrossRef] [PubMed]

44. Lee, H.S. Mechanisms and consequences of TGF-ß overexpression by podocytes in progressive podocyte disease. Cell Tissue Res. 2012, 347, 129-140. [CrossRef] [PubMed]

45. Cisternas, P.; Vio, C.P.; Inestrosa, N.C. Role of Wnt signaling in tissue fibrosis, lessons from skeletal muscle and kidney. Curr. Mol. Med. 2014, 14, 510-522. [CrossRef] [PubMed]

46. Atkinson, J.M.; Pullen, N.; Johnson, T.S. An inhibitor of thrombin activated fibrinolysis inhibitor (TAFI) can reduce extracellular matrix accumulation in an in vitro model of glucose induced ECM expansion. Matrix Biol. 2013, 32, 277-287. [CrossRef]

47. Takemoto, M.; Asker, N.; Gerhardt, H.; Lundkvist, A.; Johansson, B.R.; Saito, Y.; Betsholtz, C. A new method for large scale isolation of kidney glomeruli from mice. Am. J. Pathol. 2002, 161, 799-805. [CrossRef] 